\title{
Inverse Design of Fe-Based Bulk Metallic Glasses Using Machine Learning
}

\author{
Junhyub Jeon ${ }^{1}$, Namhyuk Seo ${ }^{1}$, Hwi-Jun Kim ${ }^{2}$, Min-Ha Lee ${ }^{3}$, Hyun-Kyu Lim ${ }^{4} \mathbb{D}$, Seung Bae Son ${ }^{1}$ and \\ Seok-Jae Lee ${ }^{1, *}$
}

check for updates

Citation: Jeon, J.; Seo, N.; Kim, H.-J.; Lee, M.-H.; Lim, H.-K.; Son, S.B.; Lee, S.-J. Inverse Design of Fe-Based Bulk Metallic Glasses Using Machine Learning. Metals 2021, 11, 729. https: / / doi.org/10.3390/ met11050729

Academic Editor: Tadeusz Kulik

Received: 25 March 2021

Accepted: 27 April 2021

Published: 28 April 2021

Publisher's Note: MDPI stays neutral with regard to jurisdictional claims in published maps and institutional affiliations.

Copyright: (c) 2021 by the authors. Licensee MDPI, Basel, Switzerland. This article is an open access article distributed under the terms and conditions of the Creative Commons Attribution (CC BY) license (https:/ / creativecommons.org/licenses/by/ $4.0 /)$.
1 Division of Advanced Materials Engineering, Jeonbuk National University, Jeonju 54896, Korea; jeonjunhyub@jbnu.ac.kr (J.J.); tjskagur@jbnu.ac.kr (N.S.); minikid@jbnu.ac.kr (S.B.S.)

2 Liquid Processing \& Casting R\&D Group, Korea Institute of Industrial Technology, Incheon 21999, Korea; khj@kitech.re.kr

3 KITECH North America, Korea Institute of Industrial Technology, 2833 Junction Ave. Suite 207, San Jose, CA 95134, USA; mhlee1@kitech.re.kr

4 Advanced Process and Materials R\&D Group, Korea Institute of Industrial Technology, Incheon 21999, Korea; hklim@kitech.re.kr

* Correspondence: seokjaelee@jbnu.ac.kr; Tel.: +82-63-270-2298

\begin{abstract}
Fe-based bulk metallic glasses (BMGs) are a unique class of materials that are attracting attention in a wide variety of applications owing to their physical properties. Several studies have investigated and designed the relationships between alloy composition and thermal properties of BMGs using an artificial neural network (ANN). The limitation of the wide-scale use of these models is that the required composition is yet to be found despite numerous case studies. To address this issue, we trained an ANN to design Fe-based BMGs that predict the thermal properties. Models were trained using only the composition of the alloy as input and were created from a database of more than 150 experimental data of Fe-based BMGs from relevant literature. We adopted these ANN models to design BMGs with thermal properties to satisfy the intended purpose using particle swarm optimization. A melt spinner was employed to fabricate the designed alloys. X-ray diffraction and differential thermal analysis tests were used to evaluate the specimens.
\end{abstract}

Keywords: Fe-based bulk metallic glasses; materials design; machine learning; artificial neural network; inverse design

\section{Introduction}

Fe-based BMGs have vast industrial application potential in electronics, magnetics, and aerospace industries owing to their high mechanical strength, heat resistance, strong corrosion resistance, and excellent soft magnetic properties [1-4]. The heat resistance of the Fe-based BMGs is determined by the crystallization temperature and glass transition temperature. When the temperature surrounding BMGs exceeds the crystallization temperature, BMGs transform into a crystal structure. This causes a decline in heat resistance, mechanical properties, and corrosion resistance. Thus, it is important to predict the thermal properties of Fe-based BMGs. The thermal properties of Fe-based BMGs depend on their alloy composition. This is key for regulating the composition ratio to design Fe-based BMGs. To understand and control the effect of composition on thermal properties, diverse research has been conducted [5-19].

Classical alloy modelling methods are generally based on a "trial-and-error" process that requires considerable time, effort, and costs. In the case of ANN, one of the latest statistical modelling methods, it is possible to predict the properties of various alloys with less time and cost through existing data. Owing to these advantages, researchers have applied ANN to predict the properties of metallic glasses [1,20-34]. Keong et al. predicted the crystallization temperature of Ni-P based amorphous alloys [20]. Cai et al. 
predicted the reduced glass transition temperature of $\mathrm{Zr}-\mathrm{Al}-\mathrm{Ni}-\mathrm{Cu}$ BMGs [21]. The alloy design using ANN could predict and design novel alloys without experimentation and cost. However, finding specific composition pairs and target values using combinations of input parameters remains an issue.

One promising scheme for optimizing tools for material discovery is the metaheuristic method. The metaheuristic method is an approximate search method for solving complex optimization problems [35]. Metaheuristic methods include genetic algorithm (GA), particle swarm optimization (PSO), and ant colony optimization. To design new materials, several studies have adopted the metaheuristic method [36-43]. Anijdan et al. used a GA model with an ANN to design an Al-Si casting alloy [36]. Shojaeefard et al. reported the welding process between AA7075 and AA5083 using PSO with ANN [37]. Ming et al. proposed a modified $\mathrm{Mg}-\mathrm{Li}-\mathrm{Al}$ alloy using $\mathrm{PSO}$ with an ANN [38]. These previous studies prove the possibility of discovering new Fe-based BMGs according to a similar modelling approach.

The goal of the present study is to propose the inverse design method using both ANN model and PSO model for the alloy design of Fe-based BMGs. We gathered a dataset containing the composition and thermal properties of Fe-based BMGs from the literature to build the ANN model. A few alloy compositions were proposed using PSO modeling and their thermal properties were experimentally validated. This study was performed to show one of the possible numerical methods to determine the Fe-based BMG composition, not to find a certain composition with target properties.

\section{Overall Process to Design New Alloys}

Figure 1 shows the four main steps to design the Fe-based BMGs in the present study. The first step was to collect and refine the database of Fe-based BMGs for generating the ANN. The second step was to learn and select the ANN for predicting the thermal properties of Fe-based BMGs. The next step was to invert the design of the ANN using a metaheuristic method to suggest the composition of Fe-based BMGs. The final step is to fabricate the Fe-based BMGs samples for experimental verification. The details of each step are described in the following sections.

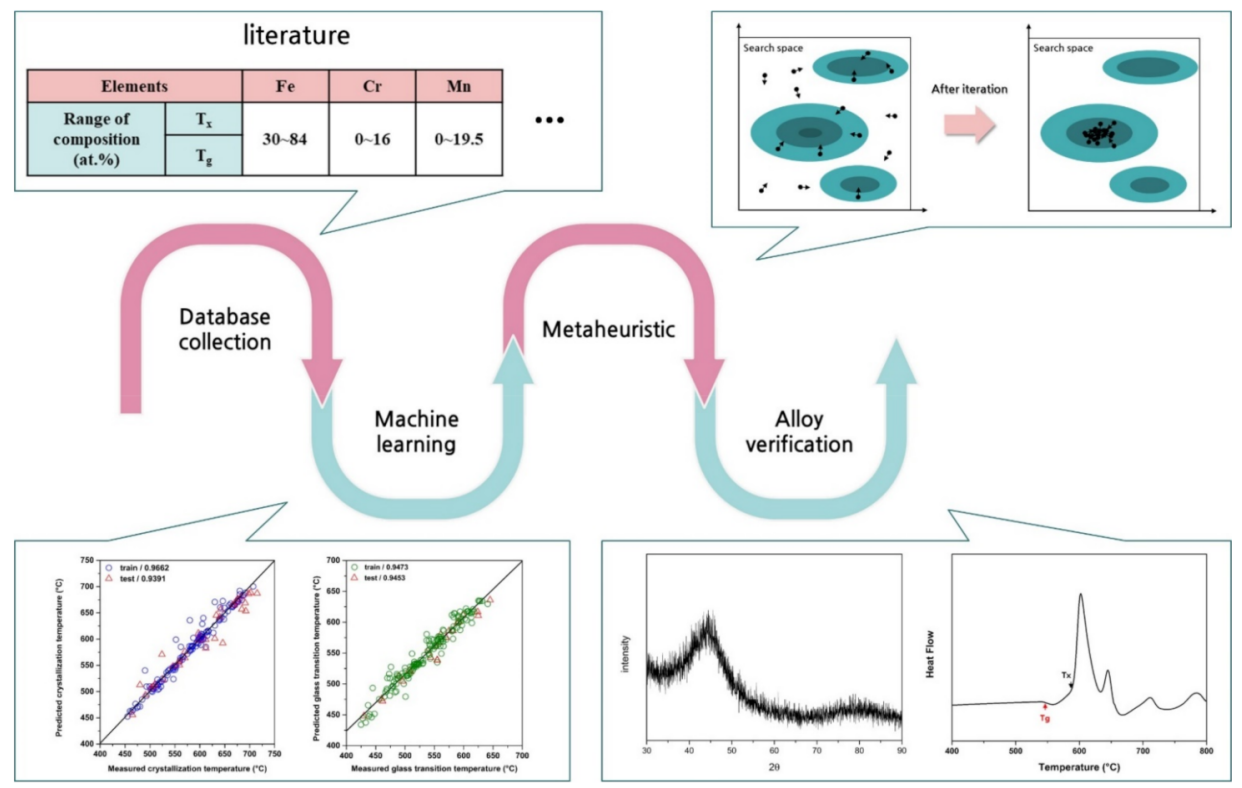

Figure 1. Process of Fe-based BMGs design.

\subsection{Database Collection}

The datasets for the Fe-based BMGs were gathered from the usable data in the published literature [44,45]. Datasets were constructed with 16 compositions (Fe, Cr, Mn, Mo, 
$\mathrm{B}, \mathrm{C}, \mathrm{Ni}, \mathrm{Co}, \mathrm{W}, \mathrm{P}, \mathrm{Si}, \mathrm{Y}, \mathrm{Zr}, \mathrm{Al}, \mathrm{Nb}$, and $\mathrm{Hf}$ ) and thermal properties, including crystallization temperature $\left(T_{x}\right)$ and glass transition temperature $\left(T_{g}\right)$. The ranges of the composition and thermal properties are listed in Table 1.

Table 1. Range of the composition and thermal properties for the dataset used in this study.

\begin{tabular}{|c|c|c|c|c|}
\hline Variable & Minimum & Maximum & Average & Deviation \\
\hline Cr (at.\%) & 0 & 16 & 2.7 & 5.0 \\
\hline Mn (at.\%) & 0 & 19.5 & 1.2 & 4.6 \\
\hline Mo (at.\%) & 0 & 16 & 4.7 & 5.4 \\
\hline B (at.\%) & 0 & 24 & 12.3 & 7.7 \\
\hline C (at.\%) & 0 & 18 & 5.0 & 6.0 \\
\hline Ni (at.\%) & 0 & 36 & 0.7 & 3.9 \\
\hline Co (at.\%) & 0 & 36 & 3.9 & 7.4 \\
\hline W (at.\%) & 0 & 4 & 0.2 & 0.5 \\
\hline P (at.\%) & 0 & 13 & 3.0 & 4.6 \\
\hline Si (at.\%) & 0 & 9.9 & 1.4 & 2.3 \\
\hline Y (at.\%) & 0 & 6 & 1.0 & 1.7 \\
\hline $\mathrm{Zr}($ at.\%) & 0 & 10 & 1.6 & 3.4 \\
\hline $\mathrm{Al}($ at.\%) & 0 & 4 & 0.2 & 0.6 \\
\hline $\mathrm{Nb}$ (at.\%) & 0 & 8 & 1.2 & 1.9 \\
\hline Hf (at.\%) & 0 & 5 & 0.2 & 1.0 \\
\hline $\mathrm{T}_{\mathrm{x}}\left({ }^{\circ} \mathrm{C}\right)$ & 455 & 715 & 550.0 & 55.6 \\
\hline $\mathrm{T}_{\mathrm{g}}\left({ }^{\circ} \mathrm{C}\right)$ & 374 & 645 & 600.8 & 68.0 \\
\hline
\end{tabular}

\subsection{ANN Model Learning}

ANN learning is the process of seeking the optimal weight factors to represent the best performance between input and output data. Hyper-parameters, including the number of layers, activation function, optimizer, and dataset separation, are the main factors in ANN model learning. In this study, we changed the number of layers from 1 to 2 and the neurons from 1 to 100 . The datasets were separated into $70 \%, 15 \%$, and $15 \%$ for training, validation, and testing, respectively. The rectified linear unit (ReLU) function was applied to the hidden layers, while the linear transfer function (purelin) was employed to the output layer. Ridge regression and early stopping were used to suppress overfitting. Two ANN models were trained for prospect $T_{x}$ and $T_{g}$, respectively. The schematic structure of the ANN model is illustrated in Figure 2. The ANN model structure with the number of layers and neurons was determined using the coefficient of determination $\left(R^{2}\right)$ value.

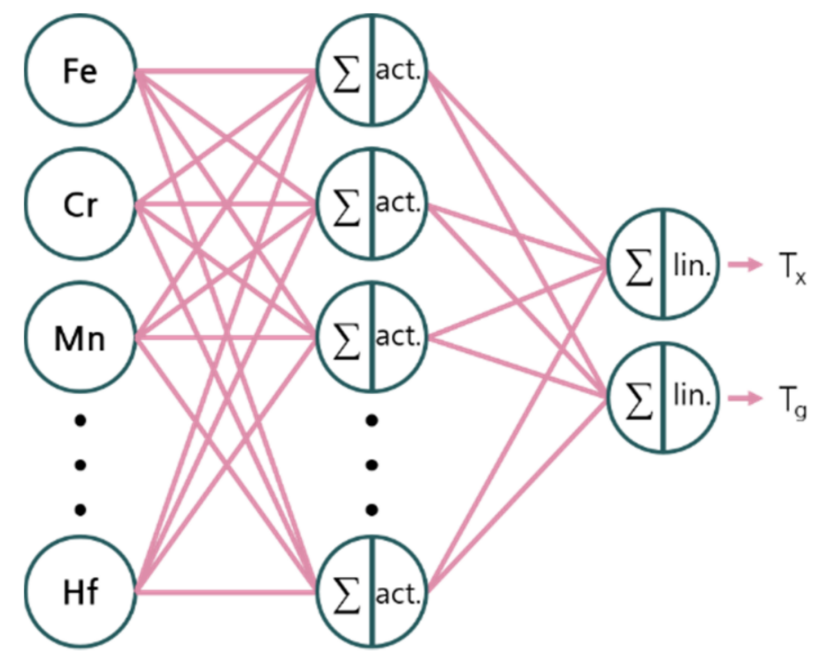

Figure 2. Schematic structure of the ANN model. 


\subsection{Inverse Design}

Although the ANN model can predict the thermal properties of Fe-based BMGs, a long calculation time is required because of the diversity and complexity of the combination of composition factors. The inverse design using metaheuristic algorithms offers a key to rapidly finding a composition in the expansive space of the mixtures of composition. In this study, PSO was adopted as a metaheuristic algorithm for the inverse design of Fe-based BMGs. The target $T_{x}$ was limited from 550 to $600{ }^{\circ} \mathrm{C}$, while the target $T_{g}$ ranged from 520 to $570{ }^{\circ} \mathrm{C}$.

\subsection{Experimental Verification}

Fe powder with a purity of $99.9 \%$ and average particle size (APS) of $<75 \mu \mathrm{m}, \mathrm{Cr}$ powder with a purity of $99 \%$ and APS of $<140 \mu \mathrm{m}$, Mo powder with a purity of $99.95 \%$ and APS of 3-7 $\mu \mathrm{m}$, B powder with a purity of $99 \%$ and APS of 1-2 $\mu \mathrm{m}$, graphite powder with a purity of $99 \%$ and APS of 7-11 $\mu \mathrm{m}$, Mn powder with a purity of $99.6 \%$ and APS of $<20 \mu \mathrm{m}$, Ni powder with a purity of $99.9 \%$ and APS of 3-7 $\mu \mathrm{m}$, and P powder with purity $98.9 \%$ and APS of $<140 \mu \mathrm{m}$ were mechanically alloyed using a high-energy ball mill (a Pulverisette-5 planetary mill) at $250 \mathrm{rpm}$ for $24 \mathrm{~h}$. Tungsten carbide balls with a diameter of $10 \mathrm{~mm}$ were used for milling in a sealed cylindrical SKD-11 tool steel jar with a ball-to-powder ratio of 30:1 under an argon atmosphere. Arc melting was selected to make a bulk sample for the melt spinner. The milled powder alloys were packed into a cylindrical steel die with an inner diameter of $200 \mathrm{~mm}$, an outer diameter of $600 \mathrm{~mm}$, and a height of $800 \mathrm{~mm}$. The milled powder was compressed to $10 \mathrm{MPa}$. The green compacts were arc melted under an argon atmosphere. Fe-based BMG ribbons were produced using a melt spinner with a $4000 \mathrm{rpm}$ copper rotating wheel and argon atmosphere. Differential thermal analysis (DTA) was carried out using a thermal analyzer (TG-DTA, TG-8121, Rigaku, Tokyo, Japan) with a heating rate of $0.64{ }^{\circ} \mathrm{C} / \mathrm{s}$. The phase state of the specimens was qualitatively analyzed using X-ray diffraction (XRD, MAX-2500, Rigaku, Tokyo, Japan) and selected area electron diffraction (SAED, JEM-ARM200F, JEOL, Tokyo, Japan).

\section{Results and Discussion}

The two-layered ANN model was successfully learned with extremely reliable $\mathrm{R}^{2}$ values, which were $0.9662 / 0.9391$ (train/test) for $\mathrm{T}_{\mathrm{x}}$ and $0.9473 / 0.9453$ (train/test) for $\mathrm{T}_{\mathrm{g}}$, respectively. The optimal structures of the ANN models were 7-64-58-1 and 7-53-50-1 for $\mathrm{T}_{\mathrm{x}}$ and $\mathrm{T}_{\mathrm{g}}$, respectively. We proposed four new chemical compositions of Fe-based BMGs to satisfy the restricted ranges of the thermal properties. The suggested compositions are summarized in Table 2.

Table 2. Fe-based BMG alloys proposed by inverse design.

\begin{tabular}{ccccc}
\hline Variable & AP1 & AP2 & AP3 & AP4 \\
\hline Cr (at.\%) & 0.6 & 0.2 & 0.3 & 0 \\
Mo (at.\%) & 2.6 & 1.4 & 1.6 & 8.6 \\
B (at.\%) & 20.2 & 20.1 & 22.1 & 25.6 \\
C (at.\%) & 12.8 & 9.9 & 10.2 & 9.8 \\
Mn (at.\%) & 0 & 12.1 & 0 & 0 \\
Ni (at.\%) & 0 & 0 & 1.0 & 0 \\
P (at.\%) & 0 & 0 & 0 & 5.4 \\
Fe $($ at. $\%)$ & Bal. & Bal. & Bal. & Bal. \\
$\mathrm{T}_{\text {x_cal }\left({ }^{\circ} \mathrm{C}\right)}$ & 568.5 & 571.5 & 572.3 & 624.1 \\
$\mathrm{~T}_{\text {g_cal }\left({ }^{\circ} \mathrm{C}\right)}$ & 564.0 & 530.2 & 557.6 & 610.9 \\
$\mathrm{~T}_{\text {x_exp }\left({ }^{\circ} \mathrm{C}\right)}$ & 587.4 & 590.6 & 605.6 & 589.7 \\
$\mathrm{~T}_{\text {g_exp }\left({ }^{\circ} \mathrm{C}\right)}$ & 548.3 & 529.7 & 568.8 & 553.3 \\
\hline
\end{tabular}

Figure 3a shows the XRD patterns of the designed alloy samples, whereas Figure $3 b$-e shows the DTA results to verify the $T_{x}$ and $T_{g}$ values. Figure 4 shows SAED results that have metallic glasses phase formation. In the XRD results, a small amount of crystal 
structure was detected. However, the metallic glass phase formation was confirmed through SAED results showing a metallic glass selected area electron diffraction pattern without lattice fringes. The measured results are compared in Table 2.
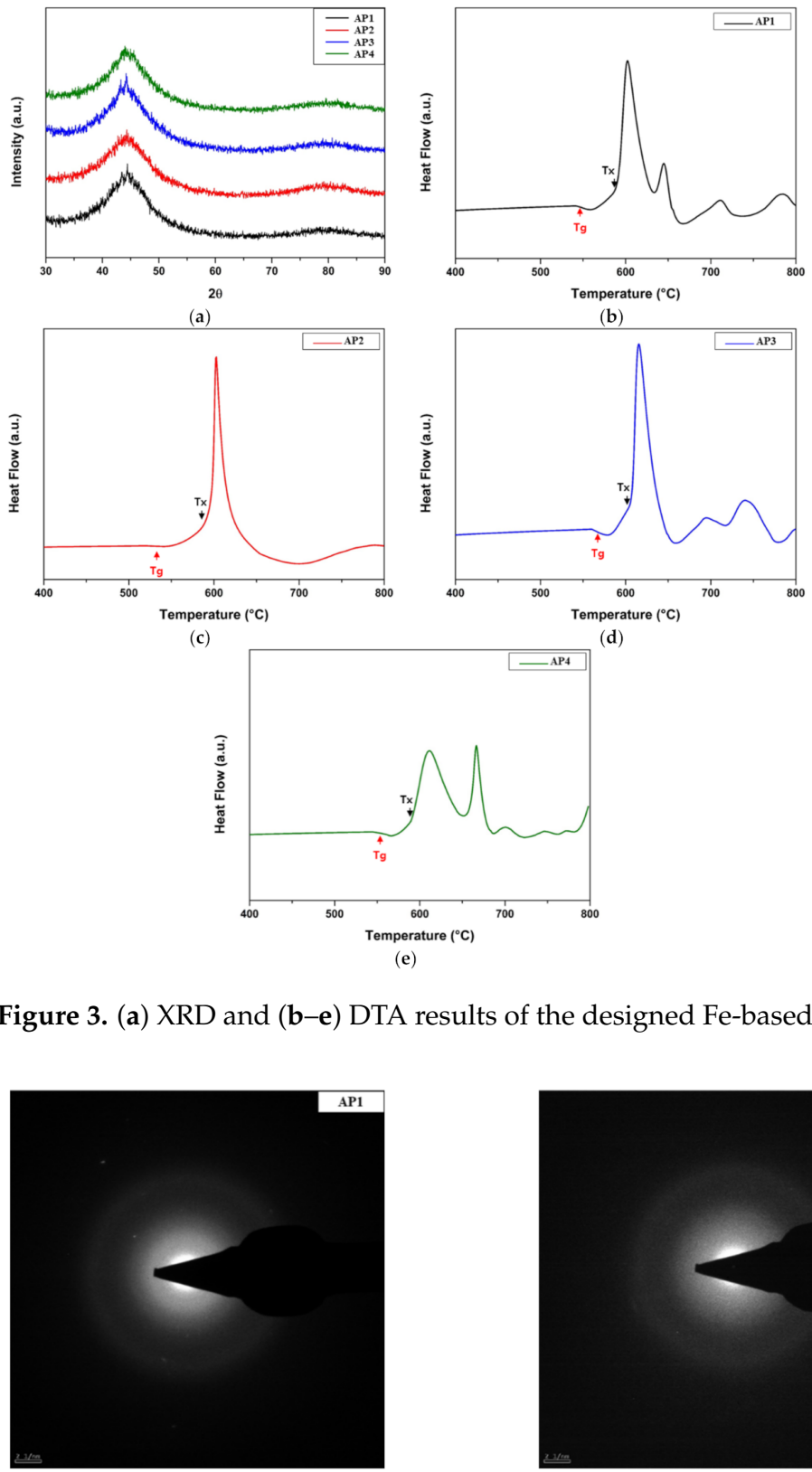

(d)

(a)

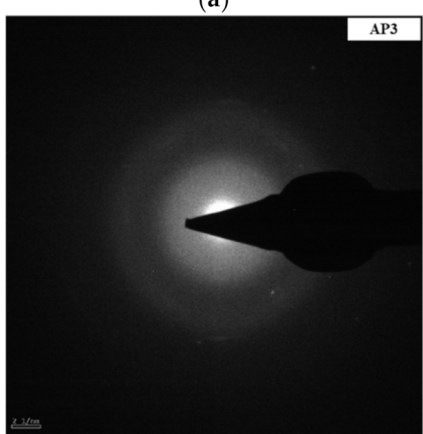

(c)

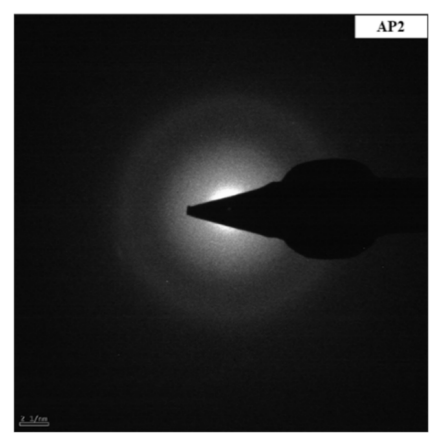

(b)

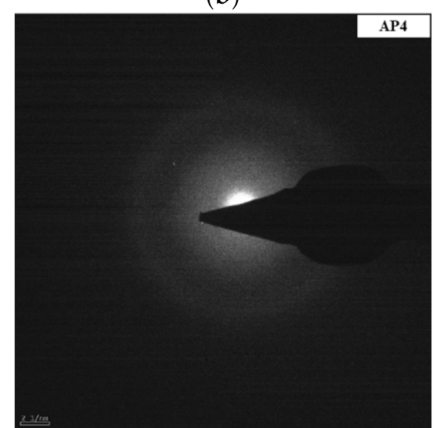

(d)

Figure 4. (a-d) Selected area electron diffraction of the designed Fe-based BMG samples. 
In contrast, Figure 5 compares the experimental thermal properties with the predicted values to confirm the accuracy of the inverse design approach in the present study. Black circles are the literature data used to train and test the ANN. Red asterisk symbols indicate the designed Fe-based BMGs. The inverse design approach with the pair of ANN and PSO methods could provide a path for finding new Fe-based BMG alloy compositions with desirable thermal properties.

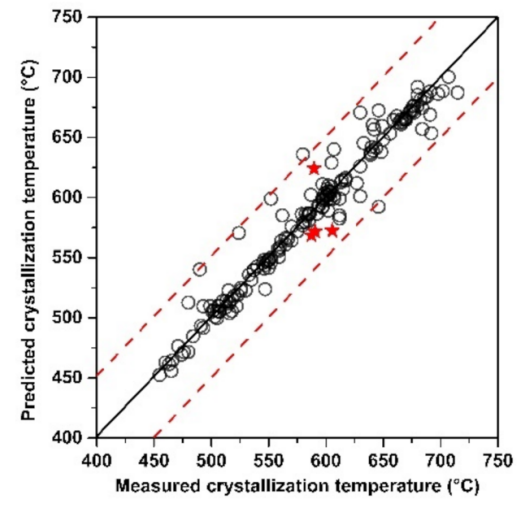

(a)

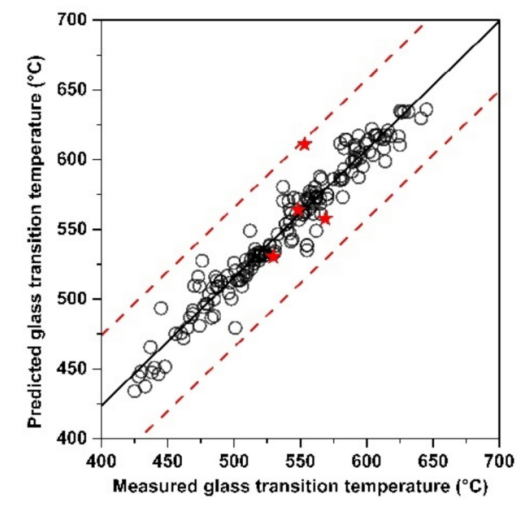

(b)

Figure 5. Predicted (a) $T_{x}$ and (b) $T_{g}$ values using the ANN model compared with the experimental data. Red asterisk symbols indicate the values of the four designed Fe-based BMG samples by the inverse design method.

\section{Conclusions}

In this study, we presented the ANN design and metaheuristic method for Fe-based BMGs and validated these predictions using powder metallurgy and melt spinning. The ANN models were organized using a dataset composed of several hundred Fe-based BMGs experiments obtained from the relevant literature. These data were used to train ANN models to predict the crystallization temperature and glass transition temperature of BMGs based on their composition. Then, PSO was adopted for obtaining the alloy composition, which has an apposite crystallization temperature and glass transition temperature. Suggested alloys were validated experimentally, with results showing that their thermal properties fall within the chose constraints. This ANN model and PSO method can facilitate the search for novel Fe-based BMGs with appropriate thermal properties despite the challenge of finding an alloy in numerous alloy combinations using ANN.

Author Contributions: Conceptualization, M.-H.L., and S.-J.L.; methodology, J.J., and N.S.; investigation, J.J., and S.B.S.; writing — original draft preparation, J.J.; writing-review and editing, S.B.S.; supervision, H.-J.K. and S.-J.L.; project administration, H.-K.L. and H.-J.K.; funding acquisition, H.-K.L. and S.-J.L. All authors have read and agreed to the published version of the manuscript.

Funding: This research was supported by the Ministry of Trade, Industry and Energy (MOTIE) and the Korea Institute for Advancement of Technology (KIAT) through the International Cooperative R\&D program (P006837). Also, this work was supported by a Korea Institute for Advancement of Technology grant, funded by the Korea Government (MOTIE) (P0002019), as part of the Competency Development Program for Industry Specialists.

Institutional Review Board Statement: Not applicable.

Informed Consent Statement: Not applicable.

Data Availability Statement: The data presented in this study are available on request from the corresponding author.

Conflicts of Interest: The authors declare no conflict of interest. 


\section{References}

1. Ward, L.; O'Keeffe, S.C.; Stevick, J.; Jelbert, G.R.; Aykol, M.; Wolverton, C. A machine learning approach for engineering bulk metallic glass alloys. Acta Mater. 2018, 159, 102-111. [CrossRef]

2. Zhang, L.-C.; Jia, Z.; Lyu, F.; Liang, S.-X.; Lu, J. A review of catalytic performance of metallic glasses in wastewater treatment: Recent progress and prospects. Prog. Mater. Sci. 2019, 105, 100576. [CrossRef]

3. Jia, Z.; Wang, Q.; Sun, L.; Wang, Q.; Zhang, L.-C.; Wu, G.; Luan, J.-H.; Jiao, Z.-B.; Wang, A.; Liang, S.-X.; et al. Attractive in situ Self-Reconstructed Hierarchical Gradient Structure of Metallic Glass for High Efficiency and Remarkable Stability in Catalytic Performance. Adv. Funct. Mater. 2019, 29, 1807857. [CrossRef]

4. Jia, Z.; Duan, X.; Qin, P.; Zhang, W.; Wang, W.; Yang, C.; Sun, H.; Wang, S.; Zhang, L.-C. Disordered Atomic Packing Structure of Metallic Glasses: Toward Ultrafast Hydroxyl Radicals Production Rate and Strong Electron Transfer Ability in Catalytic Performance. Adv. Funct. Mater. 2017, 27, 1702258. [CrossRef]

5. Park, E.S.; Lim, H.K.; Kim, W.T.; Kim, D.H. The effect of Sn addition on the glass-forming ability of Cu-Ti-Zr-Ni-Si metallic glass alloys. J. Non-Cryst. Solids 2002, 298, 15-22. [CrossRef]

6. Park, E.S.; Kang, H.G.; Kim, W.T.; Kim, D.H. The effect of Ag addition on the glass-forming ability of Mg-Cu-Y metallic glass alloys. J. Non-Cryst. Solids 2001, 279, 154-160. [CrossRef]

7. He, G.; Zhang, Z.F.; Löser, W.; Eckert, J. Effect of Ta on glass formation, thermal stability and mechanical properties of a Zr52.25Cu28.5Ni4.75A19.5Ta5 bulk metallic glass. Acta Mater. 2003, 51, 2383-2395. [CrossRef]

8. Gong, P.; Yao, K.; Zhao, S. Cu-alloying effect on crystallization kinetics of Ti41Zr25Be28Fe6 bulk metallic glass. J. Therm. Anal. Calorim. 2015, 121, 697-704. [CrossRef]

9. Lee, M.H.; Kim, W.T.; Kim, D.H.; Kim, Y.B. The effect of Al addition on the thermal properties and crystallization behavior of Ni60Nb40 metallic glass. Mater. Sci. Eng. A 2004, 375-377, 336-340. [CrossRef]

10. Yuan, G.; Inoue, A. The effect of Ni substitution on the glass-forming ability and mechanical properties of $\mathrm{Mg}$-Cu-Gd metallic glass alloys. J. Alloy Compd. 2005, 387, 134-138. [CrossRef]

11. Lee, W.; Lee, S.J. Prediction of Jominy curve using artificial neural network. J. Korean Soc. Heat Treat. 2018, 31, 1-5.

12. Seo, N.; Jeon, J.; Choi, S.; Moon, Y.H.; Shon, I.J.; Lee, S.J. Microstructural and mechanical characteristics of non-equiatomic high entropy alloy FeMnCoCr Prepared by spark plasma sintering. Arch. Metall. Mater. 2020, 3, 1005-1009.

13. Choi, S.; Jeon, J.; Seo, N.; Moon, Y.H.; Shon, I.J.; Lee, S.J. Effect of composition on strain-induced martensite transformation of FeMnNiC alloys fabricated by powder metallurgy. Arch. Metall. Mater. 2020, 3, 1001-1004.

14. Jeon, J.; Choi, S.; Seo, N.; Moon, Y.H.; Shon, I.J.; Lee, S.J. Effect of TiC addition on strain-induced martensite transformation and mechanical properties of nanocrystalline Fe-Mn alloy fabricated by spark plasma sintering. Arch. Metall. Mater. 2020, 4, $1249-1254$.

15. Jung, H.Y.; Yi, S. Enhanced glass forming ability and soft magnetic properties through an optimum Nb addition to a Fe-C-Si-B-P bulk metallic glass. Intermetallics 2010, 18, 1936-1940. [CrossRef]

16. Li, C.; Inoue, A. Effect of Zn addition on the crystallization process in Zr65Al7.5Ni10Cu17.5 metallic glass. J. Alloy Compd. 2001, 325, 230-235. [CrossRef]

17. Asami, K.; Qin, C.L.; Zhang, T.; Inoue, A. Effect of additional elements on the corrosion behaviour of a Cu-Zr-Ti bulk metallic glass. Mater. Sci. Eng. A 2004, 375-377, 235-239. [CrossRef]

18. Gong, P.; Yao, K.F.; Shao, Y. Effects of Fe addition on glass-forming ability and mechanical properties of Ti-Zr-Be bulk metallic glass. J. Alloy Compd. 2012, 536, 26-29. [CrossRef]

19. Bing, L.; Yanhong, L.; Ke, Y.; Jinshan, L.; Xinhui, F. Effect of yttrium addition on the non-isothermal crystallizationkinetics and fragility of Cu-Zr-Al bulk metallic glass. Thermochim. Acta 2016, 642, 105-110. [CrossRef]

20. Keong, K.G.; Sha, W.; Malinov, S. Artificial neural network modelling of crystallization temperatures of the Ni-P based amorphous alloys. Mater. Sci. Eng. A 2004, A365, 212-218. [CrossRef]

21. Cai, A.H.; Xiong, X.; Liu, Y.; An, W.K.; Tan, J.Y. Artificial neural network modeling of reduced glass transition temperature of glass forming alloys. Appl. Phys. Lett. 2008, 92, 11909. [CrossRef]

22. Ren, F.; Ward, L.; Williams, T.; Laws, K.J.; Wolverton, C.; Hattrick-Simpers, J.; Mehta, A. Accelerated discovery of metallic glasses through iteration of machine learning and high-throughput experiments. Sci. Adv. 2018, 4, eaaq1566. [CrossRef]

23. Cai, A.H.; Xiong, X.; An, W.K.; Tan, J.Y.; Luo, Y. Artificial neural network modeling for undercooled liquid region of glass forming alloys. Comp. Mater. Sci. 2010, 48, 109-114. [CrossRef]

24. Sosso, G.C.; Deringer, V.L.; Elliott, S.R.; Csányi, G. Understanding the thermal properties of amorphous solids using machinelearning-based interatomic potentials. Mol. Simul. 2018, 44, 866. [CrossRef]

25. Xiong, J.; Shi, S.Q.; Zhang, T.Y. A machine-learning approach to predicting and understanding the properties of amorphous metallic alloys. Mater. Des. 2020, 187, 108378. [CrossRef]

26. Deringer, V.L.; Bernstein, N.; Bartók, A.P.; Cliffe, M.J.; Kerber, R.N.; Marbella, L.E.; Grey, C.P.; Elliott, S.R.; Csányi, G. Realistic atomistic structure of amorphous silicon from machine-learning-driven molecular dynamics. J. Phys. Chem. Lett. 2018, 9, 2879-2885. [CrossRef]

27. Majid, A.; Ahsan, S.B.; Tariq, N.U.H. Modeling glass-forming ability of bulk metallic glasses using computational intelligent techniques. Appl. Soft Comput. 2015, 28, 569-578. [CrossRef] 
28. Wang, Q.; Jain, A. A transferable machine-learning framework linking interstice distribution and plastic heterogeneity in metallic glasses. Nat. Commun. 2019, 10, 5537. [CrossRef] [PubMed]

29. Tripathi, M.K.; Chattopadhyay, P.P.; Ganguly, S. Evolutionary intelligence in combinatorial design and synthesis of bulk metallic glasses by mechanical alloying. Mater. Manuf. Processes. 2017, 32, 1056-1066. [CrossRef]

30. Cai, A.H.; Liu, Y.; An, W.K.; Zhou, G.J.; Luo, Y.; Li, T.L.; Li, X.S.; Tan, X.F. Prediction of critical cooling rate for glass forming alloys by artificial neural network. Mater. Des. 2013, 52, 671-676. [CrossRef]

31. Kumar, S.D.V.; Karuppanan, S.; Ovinis, M. Failure pressure prediction of high toughness pipeline with a single corrosion defect subjected to combined loadings using artificial neural network (ANN). Metals 2021, 11, 373. [CrossRef]

32. Jha, R.; Dulikravich, G.S. Discovery of new Ti-based alloys aimed at avoiding/minimizing formation of $\alpha^{\prime \prime}$ and $\omega$-phase using CALPHAD and artificial intelligence. Metals 2021, 11, 15. [CrossRef]

33. Jedamski, R.; Epp, J. Non-destructive micromagnetic determination of hardness and case hardening depth using linear regression analysis and artificial neural networks. Metals 2021, 11, 18. [CrossRef]

34. Ryu, H.; Kim, S. Gradually tunable conductance in TiO2/Al2O3 bilayer resistors for synaptic device. Metals 2021, 11, 440. [CrossRef]

35. Osman, I.H.; Kelly, J.P. Meta-Heuristics: An Overview; Kluwer Academic Publishers: Boston, MA, USA, 1996.

36. Anijdan, S.H.M.; Bahrami, A.; Hosseini, H.R.M.; Shafyei, A. Using genetic algorithm and artificial neural network analyses to design an Al-Si casting alloy of minimum porosity. Mater. Des. 2006, 27, 605-609. [CrossRef]

37. Shojaeefard, M.H.; Behnagh, R.A.; Akbari, M.; Givi, M.K.B.; Farhani, F. Modelling and pareto optimization of mechanical properties of friction stir welded AA7075/AA5083 butt joints using neural network and particle swarm algorithm. Mater. Des. 2013, 44, 190-198. [CrossRef]

38. Ikeda, Y. A new method of alloy design using a genetic algorithm and molecular dynamics simulation and its application to Nickel-based superalloys. Mater. Trans. JIM 1997, 38, 771-779. [CrossRef]

39. Song, R.G.; Zhang, Q.Z. Heat treatment technique optimization for 7175 aluminum alloy by an artificial neural network and a genetic algorithm. J. Mater. Process. Technol. 2001, 117, 84-88. [CrossRef]

40. Sun, Y.; Zeng, W.; Ma, X.; Xu, B.; Liang, X.; Zhang, J. A hybrid approach for processing parameters optimization of Ti-22Al-25Nb alloy during hot deformation using artificial neural network and genetic algorithm. Intermetallics 2011, 19, 1014-1019. [CrossRef]

41. Babu, K.K.; Panneerselvam, K.; Sathiya, P.; Noorul Haq, A.; Sundarrajan, S.; Mastanaiah, P.; Srinivasa Murthy, C.V. Parameter optimization of friction stir welding of cryorolled AA2219 alloy using artificial neural network modelling with genetic algorithm. Int. J. Adv. Manuf. Technol. 2018, 94, 3117-3129. [CrossRef]

42. Huang, C.; Jia, X.; Zhang, Z. A modified back propagation artificial neural network model based on genetic algorithm to predict the flow behavior of 5754 Aluminum alloy. Materials 2018, 11, 855. [CrossRef]

43. Yekta, P.V.; Honar, F.J.; Fesharaki, M.N. Modelling of hysteresis loop and magnetic behaviour of Fe-48Ni alloys using artificial neural network coupled with genetic algorithm. Comput. Mater. Sci. 2019, 159, 349-356. [CrossRef]

44. Suryanarayana, C.; Inoue, A. Iron-based bulk metallic glasses. Int. Mater. Rev. 2013, 58, 131-166. [CrossRef]

45. Li, H.X.; Lu, Z.C.; Wang, S.L.; Wu, Y.; Lu, Z.P. Fe-based bulk metallic glasses: Glass formation, fabrication, properties and applications. Prog. Mater. Sci. 2019, 103, 235-318. [CrossRef] 